\title{
The Determinants of Food Security among Households in Rangpur City, Bangladesh: A Logistic Regression Approach
}

\author{
Shahjahan Ali ${ }^{1} \mathrm{Md}$. Thuhid Noor ${ }^{2}$ Khandaker Jahangir Alam ${ }^{3}$
}

\begin{abstract}
The study endeavors to estimate the food security status and identify the determinants of food security among households in Rangpur City Corporation of Rangpur Division, Bangladesh. It was found that about 65 per cent of the households are food insecure; utilizing expenditure method of estimating food security status. Further analysis utilizing the binary logistic regression method identified income and age of household head as consequential determinants of food security. They impact positively on food security, implicatively insinuating that gainfully employed and older household heads incline to be food secure. Policies that can engender good business environment for the Rangpur City Corporation poor are recommended, among others.
\end{abstract}

Keywords: Food Security, Household, Logistic Regression, Rangpur, Bangladesh.

\section{Introduction}

The Regime of Bangladesh has identified food security as a consequential factor contributing to its socioeconomic stabilization and development. Bangladesh has made a steady progress in the expansion of food production. But due to the incrementing population pressure, there has been an extensive utilization of land to meet the growing demand for food. Despite the magnification in food production and its availability, food insecurity is still a major quandary mainly because of the lack of purchasing power and thus of access to food, especially for the ultra -poor community.

Food security is a concept that has been developed overtime. As to a great extent literature has spiraled, many definitions and theoretical models on household food security have been presented (Smith et al., 1992). There is something like 200 definitions and 450 indicators of food security, (Hoddinott 1999).In Africa, food crisis in the early 1970s stimulated a most important concern on the part of the International Donor society regarding supply shortfalls created by production failures due to drought and desert disturbance (Maxwell, 1992). In 1983, FAO investigation focused on food access, leading to a definition based on the balance between the demand and supply side of the food security equation: "Ensuring that all people at all times have both physical and economic access to the basic food that they need", FAO (1983). In the World Bank (1986) report, Poverty and Hunger, this concept of food security is further elaborated in terms of: 'access of all people eat all times to enough food for an active, healthy life.'

Atthe1996 World Food Summit 182 nations agreed and adopted a still more complex definition: 'Food security, at the individual, household, national, regional and global levels. Food security is achieved when all people, at all times, have physical and economic access to sufficient, safe and nutritious food to meet their dietary needs and food preferences for an active and healthy life'(FAO, 1998). This definition integrates stability, access to food availability of nutritionally adequate food and the biological utilization of food. As a consequence, an amalgamation of these definitions, with the main emphasis on availability, access, and utilization, serves as working definition in projects of international organizations.

Food security is an essential substructure for meeting sundry Millennium Development Goals (MDGs) cognate to hunger, child mortality, noetic health, disease, gender equipollence and primary edification (Gill et al., 2003); UN Standing Committee on Nutrition, 2004).The World Bank (2001) has identified three pillars underpinning food security to include food availability, food accessibility, and food utilization. Food availability means ensuring that sufficient food is available through own production. Food accessibility means poverty reduction: simply making food available is not enough because low income households must also be able to purchase it. Food utilization means ensuring a good nutritional outcome, which can be termed nutrition security. Having sufficient food will not ensure a good nutritional outcome if poor health results in frequent sickness (Doppler, 2002).

\footnotetext{
${ }^{1}$ Research Student, Department of Economics, Begum Rokeya University Rangpur, Bangladesh. Email: sabrur_eco@yahoo.com.

${ }^{2}$ Research Student, Department of Economics, Begum Rokeya University Rangpur, Bangladesh. Email:thuhidnoor@gmail.com

${ }^{3}$ Assistant Professor, Department of Economics, Begum Rokeya University Rangpur, Bangladesh. Email:nirob_eco_ru@yahoo.com

DOI: $10.9790 / 5933-0704035156$

www.iosrjournals.org

$51 \mid$ Page
} 
Food security is a complex phenomenon attributable to a range of factors that vary in importance across geographic and social boundaries and the concept is multi-dimensional, providing valuable insights into the nature and extent of a population's food situation (IAWG, 1998).

Bangladesh is at the cross-roads in its efforts to achieve food security for its people. Over the past 30 years or so, Bangladesh had made consequential achievement in food grain production and food availability. But increases in cereal production have not been accompanied by significant rises in the availability of other foods. The accentuation of country's food self-sufficiency drive has been on carbohydrate production (through rice and wheat) to the neglect of other macronutrients (proteins and essential fats) and all other micronutrients (Gill et al., 2003). Today, though people in Bangladesh are not dying of hunger, more people are becoming stunted with reduced phrenic and physical capacity. Malnutrition is one of the major public health problems in the country. Demographic and Health Survey (DHS) 2014, has revealed that only 38 percent of the pre-school age children in the country are nutritionally normal (i.e., not malnourished) (DHS; 2014) and UNICEF; 2016). Normal diet of Bangladeshi people is also seriously imbalanced; carbohydrates contribute nearly 74 per cent to the total dietary energy and 57 per cent by protein (BBS, 2011).

The definitions of food security make it clear that the concept of food problem is an involutes one with many dimensions. At one level the concern is with national food security, which is the ability of countries to produce or import sufficient food every year to meet their requisite for both private and public distribution. At another level, the concern is more with the problem of malnutrition. Much of the studies on this topical issue have fixated on urban households.

There are different confronts to acquire food security at equally individual and household level. These confronts include improved human capital, size of the household, political stability and conflicts, formal and informal social safety nets, access to basic public supplies and cash income (in urban areas mainly). The argument is supported by various empirical findings of prior studies conducted for food security. As far as human capital variable is concerned, its value depends on five main types of investments in human beings, which include: health and nutrition, migration of people in search of new jobs, on the job training, and study programmes for adults, extension services in agriculture and formal education sector (Theodore, 1961). All these factors are usually considered as important elements of human capital, but most of the empirical studies call attention on fifth dimension that is formal education.

Kidane (2004) conducted research with primary data techniques to analyze determinants of food security in Ethiopia. The study found out that educational attainment of even primary level can significantly affect households' food security status. It can moreover affect both present and future income of the family. Education also has other important component of human capital that is the purchasing efficiency, food knowledge and meal preparation skills of the main food purchasers and preparer of the family.

Rose et al. (1998) investigated determinants of household food security in United States of America (USA). According to the results of the analysis an inverse relationship exists between schooling and food insecurity. High school graduates are less likely to be food insufficient even when the effects of income were controlled. Endogenous growth theory endorsed the perception of human capital according to which educational attainment is considered as a mean to achieve economic growth. But economic development is not the ultimate objective but an intermediate goal to ensure human freedom from deprivation of basic needs of life (Burchi, 2006). Size of the household is the other major variable that can affect food security status of the family.

Amaza (2006) analyzed factors affecting food security at household level in Nigeria. Logistic regression results showed that chances of household's food insecurity status increase as the number of dependent family members' increases overtime. The larger the dependency ratio, the higher is the burden on active members to meet the cost of minimum household nutrition and, hence the higher level of food insecurity would be. Conflicts at family level frequently occur in developing countries. With the passage of time, however, the nature of these conflicts has been changed and resultantly the percentage of civilian victims has increased.

Teodosijevic (2003) assessed possible reasons and consequences of these conflicts. They found that different economic, environmental, political and cultural are the responsible factors and ultimate consequences of such conflicts. Although agriculture is less affected than industry from such conflicts, they deteriorate and in few cases completely destroy crops which may lead to hunger. Food shortages have remained the major cause behind the destruction of rural infrastructure including loss of livestock, population migrations and widespread use of mines. Social safety nets can also affect food security status of a family. Emergency food aid programs and disability pensions are the prime examples of safety nets. Often poverty reduction plans in developing countries are included in these programs. The formal form of these programs comprises food aid to poor, public provisions and formal credit and saving schemes (Subbarao et al., 1997).

Putnam (1995) investigated that informal safety nets can take various forms such as staple sharing, credits, group membership, the receipt of remittances, house sharing, and lending of farms and animals. These connections are broad and effective within extended families because they depend on social trust. These social connections can surely reduce the probability household being food insecure. These are tools that reduce 
exposure to adverse shocks, and enhance the ability to tackle these shocks which may help in strengthening the social capital. Actually "social capital refers to the features of social organization such as networks, norms and social trust that facilitate coordination and cooperation for mutual benefit" (Putnam, 1995).

Woolcock and Naryan (2003) examined that education can play a vital role in making social bonds stronger not only through text books that a person reads during academic period but many other texts play important role in creating awareness of being social and enlarge spirit of brotherhood. In rural areas, community action can play successful role in diminishing food poverty because the larger the social nets the larger is the possibility to find assistance in food emergencies.

\subsection{The Study Area}

\section{Methodology}

The study was conducted in Rangpur City Corporation of Rangpur Division in Bangladesh. Rangpur is the one of the seventh metropolitan cities of Bangladesh. Rangpur is located at the North-Western of the country and considered as the center of northwestern Bangladesh. It was one of the oldest Municipality in Bangladesh, which was established in the year 1869. Rangpur declared as a District headquarter as on 16 December 1769. Rangpur Pauroshava was declared Rangpur City Corporation. The Local Government and Rural Development Ministry through a gazette notification on June 28 made the divisional town of Rangpur city corporation with effect from July 1, 2012. With this gazette notification, Rangpur has become the ninth city corporation in the country. Rangpur City Corporation is an emerging urban center and magnification rate of the urban population has been incrementing at an expeditious rate and commercialization activities have been on the incrementation placing most of the inhabitants who are mostly farmers, civil servants, handicrafts worker, and traders under economic stress.

\subsection{Sampling Procedure and Data Collection}

Rangpur City Corporation is divided into 33 areas, namely 33 wards. The population of the study was purposively drawn from respondents who are mainly farmers, traders/merchants handicrafts worker, and civil/public servants. 120 respondents were arbitrarily drawn from the four wards (Guptopara, Botla, Burirhat, and Domdoma) among 33 wards.

\subsection{Data Analysis Technique}

Data were analyzed applying descriptive statistics, food security index estimation and logistic regression analysis. Firstly, a set of brief descriptive coefficients that summarizes a given data set, which can either be a representation of the entire population or a sample. The measures used to describe the data set are measures of central tendency and measures of variability or dispersion. Measures of central tendency include the mean, median and mode, while measures of variability include the standard deviation (or variance), the minimum and maximum variables, kurtosis and skewness.

Secondly, Food security index estimation, utilizing expenditure method of Omonona, et al. (2007), was employed to relegate the respondents into food secure and food insecure households in a bid to establishing the food security status of the individual households. The formula is given as:

$\mathrm{F}_{\mathrm{i}}=$ Per capita monthly food expenditure for the ith household

$2 / 3$ designates per capita monthly food expenditure of all households

Where $F_{i}=$ Food security index. When $F_{i} \geq 1$ it implies that the ith household is food secure, but when $F_{i}<$ 1 , it implies that the ith household is food insecure. A food secure household is, therefore, that whose per capita monthly food expenditure is at least two-third of the mean per capita monthly food expenditure. On the other hand, a food insecure household is that whose per capita monthly food expenditure is less than two-third of the mean monthly per capita food expenditure.

Thirdly, the binary logistic regression was get used to determine the effects of some socioeconomic characteristics of the households on their food security status. The parameter of the logistic regression model was estimated with the Maximum Likelihood Estimation (MLE) technique. A binary replication function (food secure and food insecure) was designated and estimated by the logistic procedure. The binary logistic term is suited to models where the endogenous variable is dichotomous, which in this case are the households who are food secure and those who are food insecure.

Food security status was quantified setting a bid value of one or zero, where one represents food secure and zero represents food insecure. The logistic regression then provides a model of observing the probability of a household becoming food secure or food insecure. The logistic model is designated explicitly as:

$$
Y=b_{0}+b_{1} X_{1}+b_{2} X_{2}+b_{3} X_{3}+b_{4} X_{4}+b_{5} X_{5}+b_{6} X_{6}
$$

Where $\mathrm{Y}=$ Food security status ( 1 , if household is food secure; 0 , if household is food insecure)

$X_{1}=$ Sex of household head $($ Male $=1 ;$ Female $=0)$ 
$X_{2}=$ Householdsize (Number of dependents)

$X_{3}=$ Incomeof householdhead(Tk)

$X_{4}=$ Access to credit $($ Access $=1 ;$ No access $=0)$

$X_{5}=$ Age of householdhead(Years)

$X_{6}=$ Levelof educationof householdhead(Years)

\subsection{Descriptive Statistics Analysis}

\section{Results And Discussion}

Descriptive statistics provide a useful summary of security returns when performing empirical and analytical analysis, as they provide a historical account of return behavior. Although past information is useful in any analysis, one should always consider the expectations of future events. There are 96 male and 24 female among 120 respondents. The number of respondents having credit access is 84 , on the other hand, 36 respondents do not.

Table 1: Descriptive Statistics

\begin{tabular}{|l|l|l|l|}
\hline \multicolumn{5}{|l|}{} & Maximum & Minimum & Average \\
\hline Variables & 9 & 2 & 4.08 \\
\hline Number of Dependents & 60000 & 4000 & 16406 \\
\hline Income of Household Head & 75 & 20 & 48.15 \\
\hline Age of Household Head & 40000 & 4000 & 11012 \\
\hline Expenditure on Food & 17 & 3 & 11.95 \\
\hline Level of Education & \multicolumn{4}{|l}{} \\
\hline Source: Field Survey 2015 &
\end{tabular}

Table 1 shows the descriptive statistics. The variable number of dependents' mean value is 4.08 , and the maximum and the minimum value are 9 and 2 respectively. Consequently, the average income, the maximum income and the minimum income of household head are respectively Tk. 16,406, Tk. 60,000, and Tk. 4,000. Similarly, the respondents' average age, maximum age and minimum age are respectively $48.15,75$ and 20 . The monthly average food expenditure, the maximum food expenditure and the minimum food expenditure of the household are respectively Tk. 11012, Tk. 40,000 and Tk. 4000.

\subsection{Food Security Index Analysis Results}

This analysis evaluates the food security status of the households using their mean per capita expenditure on food phased in deciles (Table 2).

Table 2: Food Security Line for the Households

\begin{tabular}{|l|l|}
\hline \multicolumn{2}{|l|}{} \\
\hline Deciles & Mean Per Capita Food Expenditure (MPCFE) in Tk. \\
\hline First & 1983.09 \\
\hline Second & 1813.19 \\
\hline Third & 1946.66 \\
\hline Fourth & 1625.00 \\
\hline Fifth & 4816.66 \\
\hline Sixth & 4966.66 \\
\hline Seventh & 1748.33 \\
\hline Eighth & 4016.66 \\
\hline Ninth & 2081.11 \\
\hline Tenth & 2016.53 \\
\hline Eleventh & 2400.13 \\
\hline Twelfth & 2000.14 \\
\hline Total & 31414.16 \\
\hline 2/3 MPCFE & 20942.77 \\
\hline Note: TK. 78.50 $=$ US \$ 1 \\
\hline Source: Calculation from Field Survey Data, 2015. \\
\hline
\end{tabular}

The analysis ascertained that more than a moiety of the respondents $(65 \%)$ are food insecure since their monthly per capita food expenditure falls below two-third (2/3) of the mean monthly per capita food expenditure.

\subsection{Logistic Regression Analysis Result}


The Determinants of Food Security among Households in Rangpur City, Bangladesh: A Logistic...

This analysis identified the factors affecting the ability of the households to secure available food supplies. The result of the analysis is demonstrated in Table 3.

Table 3 Logistic Regression Result for the Determinants of Food Security Status

\begin{tabular}{|l|l|l|l|}
\hline \multicolumn{5}{|l|}{ Explanatory Variable } & Coefficients & Standard Errors & Z-Statistics \\
\hline Sex of Household Head & 5.75 & 4.83 & 0.84 \\
\hline Number of Dependants & -5.12 & 1.46 & $3.49^{*}$ \\
\hline Income of Household Head & 3.91 & 1.19 & $3.28^{*}$ \\
\hline Access to Credit & -2.12 & 1.65 & .78 \\
\hline Age & .018 & .0738 & $4.10^{*}$ \\
\hline Level of Education & 2.23 & 1.34 & $2.99^{*}$ \\
\hline Constant & -09.13 & 3.07 & $2.97^{*}$ \\
\hline-2 log likelihood ratio & 0.00 & & \\
\hline Chi-square & 38.21 & & \\
\hline $\mathrm{R}^{2}$ & .726 & & \\
\hline$*$ Significant at 5\% level of Probability & \\
\hline Source: Calculations from the field survey data, 2015. \\
\hline
\end{tabular}

Four variables are important in explaining the food security status of the household. They are number of dependants, income of household head, age of household head, and level of education of households head. The other variables demonstrate not to be important. Number of dependants or household size has a negative impact on food security status because more dependants want more food within the households with a fixed income of household head. Income of households has positive effect on food security status suggesting that the more gainfully employed a household head is, the greater his or her chances of being food secure. This calls for profitable and sustainable occupation among the Rangpur City Corporation households.

Age of household heads also has positive effect on food security status indicating that older household heads have higher probability of being food secure. This is expected because incomes of these households are likely to be higher as a result of longer stay on their public or private activities, following the assumptions of lifecycle hypothesis (Arene, 2008). According to this hypothesis, current consumption spending is generally a matter of expected income, and this expected income, is, in principle, very similar to a higher expected income indication at a higher level of current consumption and lower level of current savings, a lower level of current consumption. The level of education has positive effects on food security status point toward that higher of level education has a greater chance to get a better job which indirectly helps to earn higher income. Higher income also has positive effects on food security status. In brief, it is yielded that age of household head, income of household head, number of dependant or household size and level of education of the households are the determinants of food security status among the households in Rangpur City Corporation.

The coefficient of determination, $\mathrm{R}^{2}$ is 72.6 percent inferring that the variation in food security status is due to the stated socio-economic characteristics of the Rangpur City Corporation households. The value of $-2 \log$ likelihood ratio has 0 , bring about that data are perfectly fitted to the model. The result further showed that the overall logistic model was significant based on the chi-square, thus representing that the explanatory variables are relevant in determining the household food security status.

\section{Causes Of Food Insecurity As Seen By The Household}

The causes of food insecurity as reported by the household include low purchasing power, inefficient tax system for urban development, related to seasonal occupation and seasonal food price fluctuation (Table, 4).

Table 4: Households Uprated Common Causes of Food Insecurity

\begin{tabular}{|l|l|l|}
\hline & ${ }^{1}$ Causes & Percentage \\
\hline 1 & Low Purchasing Power & 84 \\
\hline 2 & Seasonal Occupation & 71 \\
\hline 3 & Seasonal Food Price Fluctuation & 45 \\
\hline${ }^{1}$ Households indicated more than one causes \\
\hline \multicolumn{2}{|l|}{ Source: Calculations from the field survey data, 2015. } \\
\hline
\end{tabular}

The most important causes of food insecurity are low purchasing power, inefficient tax system for urban development, seasonal occupation and seasonal food price fluctuation based on the respondents' view. Government's lack of interest to increase salaries and wages of public servants to match with the inflationary trend in the country has adverse impact on their purchasing power. There is an important reason that about 71 percent people are appointed on seasonal occupation which they lost after the end of the season in which they are appointed. 


\section{Conclusion And Recommendations For Policy}

The study has found that majority (65\%) of households in Rangpur City Corporation were food insecure during the period of the survey. Consistent with a priori expectation and findings from previous studies, age of households head, income of households head and the level of education of households head were found to significantly influence household food security in the study area positively. However, number of dependants or household size was found to influence food security negatively at the household level. The causes of food insecurity in the study area are low purchasing power, inefficient tax system for urban development, related to seasonal occupation and seasonal food price fluctuation.

In the light of the findings from the study, it is recommended that the income gap between the rich and poor in the Rangpur City Corporation area is one of the main objectives of even distribution of income, improved food security, and poverty reduction. Employment creation and income generation may contribute to shrink this gap. In addition to food security and income generation contribute to improve public waste resource management, and uplift the savings and employment potentials of the marginal and low income urban dwellers who dominate such activities. Based on the results of the study, it is also recommended that complementarities such as good transportation, information and communication technology network, and housing units that will enhance the business ventures of the city corporation poor be provided since most of the household heads are at the area of stability of their lifecycle (age range within the labour force bracket), according to the utters of lifecycle hypothesis. This calls for appropriate tax management policies that will generate sufficient internal revenue to sustain these complementary infrastructures.

\section{References}

[1]. Amaza SP (2006); "Determinants and Measurements of Food Insecurity in Nigeria: Some Empirical Policy Guide", Presentation at the International Association of Agricultural Economists Conference, Gold Coast, Australia.

[2]. Arene, C.J. (2008), Agricultural Economics: A Functional Approach, Nsukka; Prize Publishers.

[3]. Arene, C.J. and G.I.O. Mbata (2008); An Analysis of the Profitability and Choice of Metropolitan Waste-use in Urban Agriculture of the Federal Capital Territory, Abuja, Nigeria. AGRIC. ECON-CZECH, 54(6), 269-275.

[4]. Bangladesh Bureau of Statistics Report (2011).

[5]. Bangladesh Demographic and Health Survey (2014).

[6]. Burchi F (2006). "Identifying the Role of Education in Socio Economic Development", International Conference on Human and Economic Recourses, Izmir, Turkey.

[7]. Doppler, W. (2002). Farming and Rural Systems Approaches. Published Lecture Material, Hohenheim. FAO, 1987: FAO Production Year Book, 1986.

[8]. FAO (1983), World Food Security: a Reappraisal of the Concepts and Approaches. Director Generals Report, Rome.

[9]. FAO, 1987: FAO Production Year Book, 1986.

[10]. FAO (2002); The World Food Summit: Five years later. Available at www.fao.org.

[11]. Gill, G., et al., (2003); Food Security and the Millennium Development Goal on Hunger in Asia, Working Paper 231, Overseas Development Institute, London, U.K.

[12]. Kidane H (2004). "Causes of Food Insecurity in Koredegaga Peasant Association, Oromiya Zone, Ethiopia", Shaping the Future of African Agriculture for Development: Proceedings of Inaugural Symposium, Kenya.

[13]. IAWG (1998); Food Insecurity and Vulnerability Information and Mapping Systems Inter Agency Working Group, IFAD, Rome.

[14]. Maxwell, S., and M. Smith. 1992. Household food security: A conceptual review. Institute of Development Studies, University of Sussex, Brighton, U.K. Mimeo.

[15]. NFSP (2001). Easy Route to Food Availability. Available at www.fao.org.

[16]. Putnam R (1995). "Bowling Alone: America's Declining Social Capital”. J. Econ. Plan. 22: 256-267.

[17]. Omonona, B.T. and G.A. Agoi; (2007). An Analysis of Food Security Situation among Nigerian Urban Households: Evidence from Lagos State, Nigeria. Journal of Central European Agriculture, 8(3), 397-406.

[18]. Rose D, Gunderson C, Oliveria V (1998). "Socio-Economic Determinants of Food Insecurity in United States: Evidence from SIPP and CSFII Datasets", Food and Rural Economic Division, United States.

[19]. Siamwalla, A. and A. Valdes (1994). Food Security in Developing Countries. International Issues, IFPRI, Washington, D.C.

[20]. Smith, J., and Nasr, J. (1992). Urban Agriculture for sustainable Cities: using idle land and water bodies as resources. Environment and Urbanization, 4(2), 141-152.

[21]. Smith, J. Ratta, A. and Nasr, J. (1996). Urban Agriculture, Foods, Jobs, and sustainable Cities. UNDP, Habitat 11 Series.

[22]. Subbarao K, Bonnerjee A, Braithwaite J, Carvalho S, Elementary D, Graham C, Thompson A (1997). Safety Net Programs and Poverty Reduction: Lessons from Cross-Country Experience. Directions in Development. The World Bank Washington, D.C.

[23]. Teodosijevic SB (2003). “Armed Conflicts and Food Security", FAO, ESA Working Paper, 03-11.

[24]. Theodore W S (1961) "Investment in Human Capital”. Am. Econ. Rev1: 1-17.

[25]. UNICEF, Global Database 2016.

[26]. United Nations Centre for Human Settlement (1989); Solid Waste Management in Low income Housing Protects: the scope for community participation. Nairobi, ISBN: 92-1-131075-6.

[27]. USDA (1997), Food Security Assessment” Economic Research Services, United States Department of Agriculture, Washington, D.C.

[28]. Woolcock M, Naryan D (2003); "Social Capital: Implications for Development". World Bank Res. Observe., 225-249

[29]. World Bank (2001), Nuts and Bolts. Downloaded at http://wbinoo18worldbank.org/rdv/food,nsf 